\title{
Direito à Vida: Aborto de Feto Anencéfalo e Eutanásia
}

\author{
Lívia Demesio de Souza ${ }^{1}$; Athena de Albuquerque Farias ${ }^{2}$; Marcos Paulo Egídio Bezerra ${ }^{3}$; Hidemburgo Gonçalves Rocha ${ }^{4}$
}

Resumo: O presente estudo tem como tema "Direito à vida em confronto com o Aborto de Feto Anencéfalo e Eutanásia", objetivando apontar as divergências existentes entre o direito à vida do nascituro e o direto à saúde física e psíquica da gestante que quando mitigado vem a ofender o conceito de dignidade da pessoa humana, que também é uma garantia constitucional. E o direito a vida digna do paciente que se encontra em estado crítico e não exerce mais nenhum dos direitos que a Constituição Federal ver como dignos, exemplo, direito a saúde, lazer, cidadania, educação, etc., restando-lhe apenas o nu e cru direito à vida, se é que pode dizer que o mesmo vive. Os temas apresentados têm grande repercussão na sociedade, engloba posicionamentos do nosso ordenamento jurídico, da Ordem dos Advogados do Brasil, de organizações religiosas e do estudante acadêmico de Direito. Questiona-se se é razoável que o ordenamento jurídico permita a recusa do aborto de feto comprovadamente anencéfalo, imprescindível à preservação da vida da gestante, e da recusa à eutanásia a pacientes que não se encontram mais em situações dignas por convicções de uma letra de lei imutável? A metodologia empregada para a realização desse estudo foi feita através de pesquisas bibliográficas, exame de livros, artigos, além de jurisprudências. Conclui-se que não há de se falar em sacrificar totalmente um direito em virtude do outro, porém na existência de conflito entre direitos deve-se haver um equilíbrio de valores para o alcance da melhor solução possível. Os direitos fundamentais precisam ser analisados com vistas à evolução histórica, cultural e científica, devendo o Estado adaptar-se ao progresso, pois o direito não pode se retardar e seguindo o pensamento de $\mathrm{M}$. PIERRE DE HARVEN “é cometer um erro ater-se ao passado e não viver com o seu tempo: o modernismo é erguido em estado de obrigação jurídica e o misoneísmo torna-se um quase-delito civil”.

Palavras-chave: Direitos fundamentais; Liberdade e vida; Aborto; Anencéfalia; Eutanásia; Conflito de direitos fundamentais.

\section{The right to life: Abortion of anencephalic fetus and Euthanasia}

\begin{abstract}
This study has the theme "Right to life in confrontation with the abortion of anencephalic fetus and euthanasia", aiming to point out the differences between the right to life of the unborn child and the right to physical and mental health of the pregnant woman that mitigated when it comes to offense the concept of human dignity, which is also a constitutional guarantee. And the right to dignified life of the patient who is in critical condition and does not exercise any of its rights to provide what the Federal Constitution see how dignity, and the right to health, leisure, citizenship, education, etc., restando- you just the naked and raw right to life, if it can say that it lives. The topics presented have great repercussions in society, encompasses positions of our legal system, the Order of Attorneys of Brazil, religious organizations and the academic student of law. Wonders whether it is reasonable that the law allows the fetus to abortion refusal proven anencephalic, essential to preserve the mother's life, and the refusal to euthanasia to patients who do not are more dignified conditions for convictions of a letter immutable law? The methodology used to conduct this study was done through literature searches, examination of books, articles, and case law. We conclude that there is to talk about totally sacrifice a right by virtue of another, but the existence of conflict between rights should be a balance of values to achieve the best possible solution. Fundamental rights need to be analyzed with a view to historical evolution, cultural and scientific, and the state must adapt to progress, because the law can not be delayed and following the thought of M. PIERRE Harven "is making a mistake to stick to the past and not live with your time: modernism is raised in a state of legal obligation and the misoneism becomes a civil quasi-delict".
\end{abstract}

Keywords: Fundamental rights; Freedom and life; Abortion; Anencephaly; Euthanasia; Fundamental rights conflict.

\footnotetext{
${ }^{1}$ Graduada em Direito pela Faculdade dos Guararapes - Pernambuco. E-mail: livia.demesio@ rocketmail.com;

${ }^{2}$ Graduada em Direito pela Faculdade dos Guararapes. Especialista em Docência do Ensino Superior pela Faculdades Integradas de Cruzeiro - Sõ Paulo. Email: athena.farias@gmail.com;

${ }^{3}$ Graduado em Direito Universidade Regional do Cariri - URCA e Especilalista em Direito das famílias pela Universidade Regional do Cariri - URCA. E-mail: marcospaulo20@bol.com.br;

${ }^{4}$ Biólogo. Doutor em Farmacologia pela Universidade Federal do Ceará - UFC. Professorr da Faculdade de Medicina do Cariri - UFCA. Email: hidemburgo.rocha@hotmail.com.
} 
Id on Line Revista Multidisciplinar e de Psicoloqia

Id on Line Multidisciplinary Journal and Psycology

\section{Introdução}

Os Direitos e Garantias Fundamentais são garantidos pela nossa Constituição como natos ao ser humano. Dentre essas garantias está o Direito à Vida, que é tido como o mais valioso, pois é a condição-mor para que o indivíduo faça uso de todos os outros direitos. Cabendo ao Estado o dever preservá-la com um determinado grau de qualidade.

Nesta linha de raciocínio a pesquisa tentou trazer argumentos sobre o início e fim da vida, e quando ela passa a não ser mais digna, ou ameaça a dignidade de outrem, ficando claro que a defesa incontestável de tal direito como em um circulo vicioso torna-se uma ofensa ao mesmo.

O tema traz duas hipóteses de direito à vida que vem a ofender a dignidade, num primeiro momento discute-se a possibilidade de abreviação do sofrimento, através da eutanásia, de alguém que já não tem mais expectativa de dignidade em decorrência de doenças graves, onde só vem a deixar o indivíduo em situação torturante, degradante e desumana e a posteriori a mantença frustrante e dolorosa de um feto inviável e sem expectativa de vida extra-uterina.

Ao longo da pesquisa discutir-se-á conceitos, legislação e vários posicionamentos.

O objetivo do presente estudo é discutir a forma como o direito está tratando a noção de vida, se toda a evolução cultural, histórica e científica está em consonância com essa visão. E porque dar atenção a novos paradigmas de como o ser humano vem ao mundo, se mantêm ou vai embora dele, de maneira a não deixar verdades, normas e direitos irrefutáveis vir a indignificar vidas não seria também um gesto de sensatez e de complacência para com a honra da vida humana?

O que não deixa de ser óbvio e inúmeras vezes discutido é que a sociedade só evolui e o direito tem por obrigação natural, aprimorar-se de modo a saber quando mitigar ou recuar um direito para não causar uma ofensa mais gravosa e irreparável a outro.

\section{Do direito à vida: breve histórico da noção de direito natural e evolução constitucional sobre a vida}

A vida, por impulso natural de sobrevivência, é o bem mais valioso para o ser humano, no contexto de todas as suas relações (social, política e jurídica). Sendo a proteção da vida e da 
Id on Line Revista Multidisciplinar e de Psicoloqia

Id on Line Multidisciplinary Journal and Psycology

integridade física do ser humano, considerada um dos fins essenciais do Estado e razão do seu surgimento, como se pode verificar na obra de Thomas Hobbes (1588-1679). Podemos também observar que a noção de direito à vida está inúmeras vezes associada à noção de um direito natural, ou seja, inato e inalienável do ser humano, como segue o pensamento de John Locke (1632-1704). Já para o direito positivo, o direito à vida é reconhecido como direito humano e fundamental, não podendo ser confundido com concepções de necessidades ou instintos, ainda que de defesa ou sobrevivência.

No âmbito da evolução constitucional brasileira, podemos verificar que na Constituição de 1824 e 1891 não havia previsão de um direito à vida, mas apenas um direito à segurança individual. Na Constituição de 1934, embora o dito direito não estivesse expressamente protegido, foi abolida a pena de morte, salvo nos casos de guerra com país estrangeiro e nos termos da legislação militar (art.113, 29). Em seguida na Constituição de 1937 o direito à vida não foi contemplado, e foram ampliadas as hipóteses de aplicação da pena de morte (art. 122, 13). Por sua vez, foi na Constituição de 1946, que surgiu o reconhecimento e proteção como direito individual do direito à vida (art. 141, caput), sendo retomado o mesmo método da Constituição de 1934, em relação a extinção da pena de morte, o que foi mantido na Constituição de 1967 (art. 150, caput e $\S 11$ ), com a ressalva de que o texto constitucional faz menção ao caso de guerra externa e não de guerra com outro país.

$\mathrm{Na}$ Constituição Federal de 1988, o direito à vida foi contemplado expressamente como direito inviolável. Em seu art. $5^{\circ}$, caput, a vida encontrou uma proteção constitucional adicional. Onde o constituinte brasileiro garante aos brasileiros e estrangeiros residentes do País a inviolabilidade do direito à vida, à liberdade, à igualdade, à segurança e à propriedade. Proclamar esse direito responde a uma exigência prévia ao ordenamento jurídico, pois trata-se de um valor supremo na ordem constitucional, que orienta, informa e dá sentido último a todos os demais direitos fundamentais. Cabendo ao Estado o dever de assegurá-lo em seu duplo sentido, sendo o primeiro agir para preservá-la em si mesma e o segundo uma vida digna com determinado grau de qualidade. Ou seja este consiste não só no direito do indivíduo não ser morto pelo Estado ou algum particular, mas também à uma vida digna, nos fazendo lembrar do fundamento constitucional da dignidade da pessoa humana previsto no art. $1^{\circ}$, III da nossa Constituição. É como se fosse uma regalia que permite ao indivíduo estabelecer um limite à atuação estatal, pois aqui há uma obrigação do Estado e de particulares em não realizar condutas 
Id on Line Revista Multidisciplinar e de Psicoloqia

Id on Line Multidisciplinary Journal and Psycology

que ofendam de alguma forma o direito à vida. Sendo de obrigação do estado assegurar aos seus cidadãos o direito de continuarem vivos e propiciá-los uma vida digna relacionada a sua subsistência.

E de acordo com Ricardo Cunha Chimenti:

São decorrências do direito de não ser morto (ou de continuar vivo):
A) Proibição de pena de morte (art. $5^{\circ}$, XLVII, a, CRFB/88);
B) Proibição do aborto;
C) Proibição da eutanásia;
D) Direito à legítima defesa (art. 23, II, CP).
Decorrem do direito às condições mínimas de sobrevivência:
A) A garantia do salário mínimo (art. 7º, IV, CRFB/88);
B) A irredutibilidade do salário (art. 7º, VI, CRFB/88);
C) O direito à saúde, à previdência e à educação. (2009; pg. 60-61)

No Estado de Direito Democrático e Social, não se permite à disponibilidade do direito à vida, por reconhecer a supremacia da dignidade da pessoa humana como seu fundamento e entender a vida como pressuposto básico para que se manifestem os outros direitos fundamentais que, em conjunto, formam o substrato mínimo necessário à dignidade humana (LEME, 2005).

Registre-se, como argumento lógico, que a própria etimologia da expressão "direito à vida digna" pressupõe uma inicial existência de vida, para a posterior obtenção da sua dignidade, sendo esta uma qualidade da vida. Resumindo, poderá haver vida sem dignidade, mas nunca dignidade sem vida (MACEDO, 2006).

Uadi Lammêgo Bulos explica que, "sem a proteção incondicional do direito à vida, os fundamentos da República Federativa do Brasil não se realizariam. Daí a Constituição proteger todas as formas de vida, inclusive a uterina.”. (2007; p.410).

Diante de toda essa discussão em torno desse direito, vamos tentar entender o que significa vida em algumas visões, como segue no próximo capítulo.

\section{Conceito de Vida}

A vida (do latim vita) tem um conceito muito amplo e admite diversas definições. Muitos filósofos tentam defini-la como um fenômeno que anima a matéria, tendo-se a idéia de que é vivo aquilo que tem capacidade de nascer, desenvolver e morrer. 
O Dicionário Aurélio da Língua Portuguesa traz o seguinte conceito: Conjunto de propriedades e qualidades graças às quais animais e plantas se mantém em contínua atividade; existência. (HOLANDA, 1994; 630)

A Lei 9.434/97 afirma que há morte com o encerramento da atividade cerebral, podendo-se concluir que a vida é a existência de atividade cerebral aplicada à pessoa humana.

José Afonso da Silva embora não dê uma definição do que seja a vida, dá uma grande explicação desse objeto de direito fundamental:

Vida, no texto constitucional (art. $5^{\circ}$, caput), não será considerada apenas no seu sentido biológico de incessante auto-atividade funcional, peculiar à matéria orgânica, mas sua acepção biográfica mais compreensiva. Sua riqueza significativa é de difícil apreensão porque é algo dinâmico, que se transforma incessantemente sem perder sua própria identidade. É mais um processo (processo vital), que se instaura com a concepção (ou germinação vegetal), transforma-se, progride, mantendo sua identidade, até que muda de qualidade, deixando, então, de ser vida para ser morte. Tudo que interfere em juízo deste fluir espontâneo e incessante contraria a vida. (2005, p. 197).

Kildare Gonçalves Carvalho conceitua Vida como:

No sentido biológico, a vida consiste no conjunto de propriedades e qualidades graças às quais os seres organizados, ao contrário dos organismos mortos ou da matéria bruta, se mantêm em continua atividade, manifestada em funções, tais como o metabolismo, o crescimento, a reação a estímulos, a adaptação ao meio, a reprodução e outras. (2008; pg. 699).

Para Alexandre de Morais: "O direito à vida é o mais fundamental de todos os direitos, já que se constitui em pré-requisito à existência e exercício de todos os demais direitos". E o inicio do direito à vida deverá ser dado pelo biológico, como explica:

\begin{abstract}
O inicio da mais preciosa garantia individual deverá ser dado pelo biológico, cabendo ao jurista tão somente, dar-lhe o enquadramento legal, pois do ponto de vista biológico a vida se inicia com a fecundação do óvulo pelo espermatozóide, resultando um ovo ou zigoto. Assim a vida viável, portanto, começa com a nidação, quando se inicia a gravidez. Conforme adverte o biólogo Botella Lluziá, o embrião ou feto representa um ser individualizado, com uma carga genética própria, que não se confunde nem com a do pai, nem com a da mãe, sendo inexato afirmar que a vida do embrião ou do feto está englobada pela vida da mãe. A constituição, é importante ressaltar, protege a vida de forma geral, inclusive uterina. $(2007 ; 31)$
\end{abstract}

Já para Uadi Lammêgo Bulos, seu significado é amplo, porque ele se conecta com outros, a exemplo dos direitos à liberdade, à igualdade, à dignidade, à segurança, á propriedade, 
à alimentação, ao vestuário, ao lazer, à educação, à saúde, à habitação, à cidadania, aos valores sociais do trabalho e da livre iniciativa. $(2007 ; 410)$.

O Superior Tribunal de Justiça entende que:

\begin{abstract}
A legislação penal sufragou o calendário gregoriano para o cômputo do prazo. $\mathrm{O}$ período do dia começa à zero hora e se completa às 24 horas. Inclui-se o dia do começo. A idade é mencionada por ano. Não se leva em conta à hora do nascimento. O dia do começo, normativamente, independe do instante da ocorrência do nascimento. Termina às $24 \mathrm{~h}$. Assim, a pessoa nascida ao meio-dia completa o primeiro dia de vida à meia-noite.
\end{abstract}

O Tribunal de Justiça de São Paulo concluiu que: "a personalidade civil do homem começa com o nascimento com vida, mas a lei põe a salvo os direitos do nascituro, uma vez que neste há vida".

Sobre a capacidade processual do nascituro o Tribunal de Justiça do Rio Grande do Sul têm entendimento que:

Ao nascituro assiste, no plano do Direito Processual, capacidade para ser parte, como autor ou como réu. Representando o nascituro, pode a mãe propor ação investigatória, e o nascimento com vida investe o infante da titularidade da pretensão de direito material, até então apenas uma expectativa resguardada.

Na visão de Jacques Robert (apud José Afonso da Silva, 2000; pg. 201):

O respeito à vida humana é há um tempo uma das maiores idéias de nossa civilização e o primeiro principio da moral médica. É nele que se repousa a condenação do aborto, do erro ou da imprudência terapêutica, a não-aceitação do suicídio. Ninguém terá o direito de dispor da própria vida, a fortiori da de outrem e, até o presente, o feto é considerado como um ser humano.

Após a exposição de definições do que é vida vos será apresentado um tema bastante polêmico, onde há quem veja como uma ofensa a esse fenômeno chamado vida.

\title{
Eutanásia: Conceito e Tipos
}


A palavra eutanásia vem do grego "euthanasia" e significa eu bom”, thanasia "morte", ou seja, "boa morte" ou "morte apropriada", tendo-se a idéia de morte provocada com o objetivo de cessar uma dor ou sofrimento.

Francis Bacon, em 1623, em sua obra "Historia Vitae et Mortis", a define como sendo o adequado tratamento às doenças incuráveis.

A eutanásia pode ser classificada de várias formas, de acordo com o critério considerado.

Quanto ao tipo de ação:

Eutanásia ativa: 0 ato deliberado de provocar a morte sem sofrimento do paciente, por fins misericordiosos.

Eutanásia passiva ou indireta: a morte do paciente ocorre, dentro de uma situação de terminalidade, ou porque não se inicia uma ação médica 
ou pela interrupção de uma medida extraordinária, com o objetivo de minorar o sofrimento.

Eutanásia de duplo efeito: quando a morte é acelerada como uma conseqüência indireta das ações médicas que são executadas visando o alívio do sofrimento de um paciente terminal.

Quanto ao consentimento do paciente:

Eutanásia voluntária: quando a morte é provocada atendendo a uma vontade do paciente.

Eutanásia involuntária: quando a morte é provocada contra a vontade do paciente.

Eutanásia não voluntária: quando a morte é provocada sem que o paciente tivesse manifestado sua posição em relação a ela.

Esta classificação, quanto ao consentimento, visa estabelecer, em última análise, a responsabilidade do agente, no caso o médico. Esta discussão foi proposta por Neukamp, em 1937.

Historicamente, a palavra eutanásia admitiu vários significados. Destacamos, a título de curiosidade, a classificação proposta na Espanha, por Ricardo Royo-Villanova, em 1928:

Eutanásia súbita: morte repentina;

Eutanásia natural: morte natural ou senil, resultante do processo natural e progressivo do envelhecimento;

Eutanásia teológica: morte em estado de graça;

Eutanásia estóica: morte obtida com a exaltação das virtudes do estoicismo;

Eutanásia terapêutica: faculdade dada aos médicos para propiciar uma morte suave aos enfermos incuráveis e com dor;

Eutanásia eugênica e econômica: supressão de todos os seres degenerados ou inúteis;

Eutanásia legal: aqueles procedimentos regulamentados ou consentidos pela lei.

No Brasil, também em 1928, o Prof. Ruy Santos, na Bahia propôs que a eutanásia fosse classificada em dois tipos, de acordo com quem executa a ação: 
Id on Line Revista Multidisciplinar e de Psicoloqia

Id on Line Multidisciplinary Journal and Psycology

Eutanásia-homicídio: quando alguém realiza um procedimento para terminar com a vida de um paciente.

Eutanásia-homicídio: realizada por médico;

Eutanásia-homicídio: realizada por familiar;

Eutanásia-suicídio: quando o próprio paciente é o executante. Esta talvez seja a idéia precursora do $\underline{\text { Suicídio Assistido. }}$

Finalmente, o Prof. Jiménez de Asúa, em 1942, propôs que existem, a rigor, apenas três tipos:

Eutanásia libertadora, que é aquela realizada por solicitação de um paciente portador de doença incurável, submetido a um grande sofrimento;

Eutanásia eliminadora, quando realizada em pessoas, que mesmo não estando em condições próximas da morte, são portadoras de distúrbios mentais. Justifica pela "carga pesada que são para suas famílias e para a sociedade";

Eutanásia econômica, seria a realizada em pessoas que, por motivos de doença, ficam inconscientes e que poderiam, ao recobrar os sentidos sofrerem em função da sua doença.

Estas idéias bem demonstram a interligação que havia nesta época entre a eutanásia e a eugenia, isto é, na utilização daquele procedimento para a seleção de indivíduos ainda aptos ou capazes e na eliminação dos deficientes e portadores de doenças incuráveis.

Kildare Gonçalves Carvalho explica que:

\begin{abstract}
A Constituição Brasileira não acolheu a eutanásia. De fato, não a recomendam o progresso da medicina e o fato de que a vida é um bem não só individual, mas também social, e o desinteresse por ela, pelo indivíduo, não há de excluí-la da proteção do direito. [...] Diferente da eutanásia é a ortotanásia, a morte decorrente do desligamento de aparelhos, ou da suspensão de tratamentos ou procedimentos que prolongam a vida de doentes em estado terminal, sem possibilidade de cura, causando-lhes dor e sofrimento. (2008; pg.700)
\end{abstract}

O conselho Federal de Medicina aprovou a Resolução n. 1.805/2006, que possibilita a pratica da ortotanásia, nos seguintes termos: “Art.1. É permitido ao médico limitar ou suspender procedimentos e tratamentos que prolonguem a vida do doente em fase terminal, de enfermidade grave e incurável, respeitada a vontade da pessoa ou de seu representante".

De acordo com Uadi Lammêgo Bulos (apud CARVALHO, 2008; pg. 700): 
O direito a vida não abre brechas para o império de artifícios médicos destinados a abreviar doenças incuráveis ou terríveis. É por esse motivo que a ordem jurídica proíbe todas as formas de manifestação da eutanásia. Ainda quando seja impossível prever ou impedir o exato momento em que alguém, sponte sua, elimina sua vida, mais certo ainda é que não é facultado ao homem dispor de sua própria morte.

\section{Aborto: Conceituação e Tipos}

\section{Conceito Médico}

Se buscarmos uma conceituação etimológica da palavra aborto, encontraremos a expressão "ab-ortus" (ab, privação e ortus, nascimento), que traz a ideia de "privar o nascimento". Provém, a palavra aborto, do termo latino "aboriri”, que significa "separar algo do lugar adequado", e é trazido para nós como sendo "a interrupção da gravidez antes de seu termo normal, seja ela espontânea ou provocada, tenha havido ou não expulsão do feto destruído" (DINIZ, 2009, p. 30).

A Organização Mundial da Saúde define abortamento como sendo a interrupção da gestação antes de 20-22 semanas ou com peso inferior a 500 gramas. Subclassifica ainda em precoce, quando ocorre até 12 semanas e tardio quando entre 12 e 20-22 semanas.

Quando o tempo de gravidez é desconhecido deve-se considerar o peso ou ainda o limite de $16 \mathrm{~cm}$ de comprimento, aceito por alguns autores.

A ciência médica distingue o termo aborto de abortamento. Para a Medicina, abortamento é o processo de perda do produto conceptual, enquanto que aborto é o próprio produto da concepção.

Cabe alertar que o produto da concepção não é apenas o feto, mas também a placenta, membranas amnióticas e cordão umbilical.

Quando ocorre óbito fetal após as 20-22 semanas, chamamos de Óbito Fetal Intra-útero, sendo sua expulsão o parto de um natimorto. Se o feto inviável, porém com mais de 20-22 semanas, nascer com vida e falecer em seguida, falasse em parto prematuro e não em aborto.

Partindo de tal explicação, vale clarear um ponto: a partir da vigésima ou vigésima segunda semanas da gestação, em que ocorrer o aborto, não mais deverá receber este nome de acordo com a nominação dada pela medicina. $\mathrm{O}$ nome adequado a esta situação é parto prematuro, pois entre as semanas 22 e 36 da gestação, o feto encontra-se em situação de prematuridade, podendo ser este parto espontâneo ou eletivo (caso em que o médico precise 
Id on Line Revista Multidisciplinar e de Psicoloqia

Id on Line Multidisciplinary Journal and Psycology

interromper a gravidez por algum motivo). Entretanto, Maria Helena Diniz, doutrinadora na área do Biodireito e de reconhecido renome, contesta este posicionamento, ao argumentar que deve ser admitida a ideia de que a interrupção do parto a qualquer tempo é aborto (DINIZ, op. cit., p. 30-31).

Sguindo o pensamento de CUNHA, a consumação do crime de aborto ocorre com a morte do feto e a interrupção da gravidez, independente se a morte deste se deu dentro ou fora da mãe. Aqui o que leva-se em conta é a interrupção da gravidez que resulta na morte do feto. E para que seja tipificado, é necessária a consciência do agente acerca da gravidez, podendo ser através desta comprovado o dolo em cometer tal conduta. (2008, p. 37).

Este crime comporta a hipótese de tentativa, sendo que esta será caracterizada quando houver a interrupção da gravidez, mas sem o resultado morte do feto (MAGALHÃES NORONHA, apud CUNHA, 2008, p. 37).

O nosso Código Penal admite a tentativa quando a agente já tiver dado início aos atos executórios e, por circunstâncias alheias a sua vontade, não consegue consumar a infração penal, devendo responder por aborto tentado. O mesmo ocorre quando o agente, executando todas as manobras necessárias para a expulsão do feto, este, mesmo tendo sido efetivamente expulso do ventre materno, consegue sobreviver.

\section{Conceito Legal}

Coelho e Jarjura, renomados médicos-legistas do Estado de São Paulo, definem aborto como sendo a interrupção da prenhez, com a morte do produto, haja ou não expulsão, qualquer que seja o seu estado evolutivo, desde a concepção até o parto.

A legislação, ao contrário da medicina, não define tempo limite para a ocorrência de aborto, aceitando a denominação desde a concepção até o termo.

Brandão afirma que o abortamento consiste, em essência, na morte do concepto antes de sua viabilidade. Quando provocado dolosamente, tipifica o crime de aborto, tratado nos artigos $124^{\circ}$ e seguintes do Código Penal Brasileiro.

Flamínio Fávero define abortamento como a interrupção da gravidez antes do termo normal, com morte do embrião, sendo indiferente sua expulsão ou não, assim como a viabilidade do produto sobre o qual incidem as manobras. 
Id on Line Revista Multidisciplinar e de Psicoloqia

Id on Line Multidisciplinary Journal and Psycology

\section{Classificação Médica}

A Medicina classifica o abortamento conforme ao tempo em que ocorre, as características do colo uterino, quanto a presença de infecção e ainda quanto a eliminação total, parcial ou não eliminação do embrião e dos anexos.

Quanto ao tempo em que ocorre o aborto ele pode ser definido como precoce (até 12 semanas de gestação) ou tardio (de 12 a 20 semanas). De maneira diversa ao Direito, quando ocorre a morte intra-útero após 20 semanas de gestação os médicos já não falam em aborto, mas sim em óbito fetal intra-útero (OFIU). Da mesma forma, o nascimento antes de 20 semanas, ainda que vivo, é aborto e após esse período, parto prematuro, ainda que o recémnascido evolua a óbito poucas horas depois (neomorto). Ao nascido sem vida após as 20 semanas denomina-se natimorto.

Para que ocorra a eliminação do aborto é necessário que o colo uterino se dilate permitindo sua expulsão. Assim, quando a mulher apresenta sangramento e dilatação cervical, ainda que por hora persista a atividade cardíaca fetal, fala-se em aborto inevitável. Entretanto, existem situações em que há sangramento sem cervico-dilatação. A estes chamamos de abortamento evitável ou ameaça de abortamento.

Uma das complicações potencialmente fatais do abortamento é a infecção. Quando há sinais de infecção denomina-se o aborto infectado. Por outro lado, na ausência de sinais e sintomas infecciosos simplesmente não se classifica quanto a este fator ou fala-se em abortamento asséptico.

Ocorrendo a eliminação completa do embrião e dos anexos (membranas, placenta) configura-se o abortamento completo. Se a expulsão for parcial, temos o abortamento incompleto. Pode ocorrer, no entanto, de não haver a eliminação espontânea do produto conceptual em até trinta dias após a morte do embrião. Falamos então em aborto retido.

\section{Classificação Legal}

Do ponto de vista legal, o aborto pode ser classificado como natural (espontâneo) ou provocado. 
Id on Line Revista Multidisciplinar e de Psicoloqia

Id on Line Multidisciplinary Journal and Psycology

O aborto espontâneo é aquele em que o próprio organismo se encarrega de realizálo, independe da vontade da mulher. Caracteriza-se pela inviabilidade natural do concepto e sua morte devido a diferentes fatores etiológicos. Observa-se que o filho é desejado, mas ocorre a interrupção da gestação por fatores impeditivos da própria natureza, sem participação da vontade.

O aborto provocado é aquele feito intencionalmente, ocasionando, então, a morte do feto por vontade da própria gestante e/ou de outrem. Subclassifica-se em legal ou criminoso:

Aborto legal é aquele que se enquadra em situações previstas e amparadas pela lei. Atualmente, no Brasil, apenas duas situações são consideradas legais: gravidez decorrente de estupro e quando este é o único meio de salvar a vida da gestante. Na primeira situação fala-se em aborto sentimental, moral ou humanitário. A segunda situação configura o chamado aborto terapêutico.

A lei não define tempo de gravidez, permitindo que nessas situações a gravidez seja interrompida a qualquer tempo de sua evolução (ovo, embrião ou feto).

No aborto sentimental o perigo deve ser real e não presumível por prognósticos. A lei oferece amparo ao aborto em situações, por exemplo, de gestação ectópica, câncer de colo uterino, formas graves de diabete, cardiopatia grave, nefropatia severa, insuficiência hepática. Instalado o perigo iminente não há necessidade de autorização judicial, pois a demora poderia caracterizar negligência, imprudência ou omissão de socorro. O médico deve dar ciência à gestante e à família. A questão deve ser discutida e assinada por pelo menos mais dois médicos, p.ex. anestesista e diretor clínico.

Ainda nesses casos, é mister a autorização expressa e formal da gestante ou de seu representante legal para que se proceda a prática do aborto. O procedimento poderá ser realizado sem o consentimento como medida de absoluta exceção.

Não é absurdo ressaltar que mesmo o aborto legal somente pode ser efetuado por médico devidamente habilitado.

No caso de estupro (conjunção carnal mediante violência física ou grave ameaça) é permitido o aborto. A violência pode ser presumida no caso da vítima ser menor de 14 anos, alienada ou débil mental, desde que isso seja de conhecimento do autor, ou ainda se a vítima for incapaz de oferecer resistência contra o agressor. 


\section{Além do aborto provocado - legal, há o aborto acidental, ou seja, aquele decorrente de um traumatismo acidental, por exemplo, atropelamento, queda de escada, acidente motociclístico. $O$ aborto decorrente de acidente também não configura crime.}

Qualquer outra prática diversa das duas previstas pelo artigo 128 Código Penal Brasileiro e de acidentes é considerado crime, como consta dos artigos 124 a 126, e 127 (forma qualificada), que são: a) Provocar aborto em si mesma ou consentir que outrem lho provoquem (Art. 124); b) Provocar aborto, sem consentimento da gestante (Art.125); c) Provocar aborto com o consentimento da gestante (Art. 126).

Portanto, o aborto eugênico, econômico, social ou estético, são práticas criminosas.

\section{Aborto Eugênico}

Eugenia é uma tentativa de melhora biológica da raça humana, mediante seleção de indivíduos portadores de características reputadas em determinado momento histórico como favoráveis ou melhores que a dos demais. Isto significa afirmar que neste caso teríamos o aborto realizado em razão de algum tipo de anomalia física ou psíquica que o feto viesse a apresentar. Caberiam, nesta hipótese, por exemplo, a anencefalia, assim como vários tipos de síndromes.

De fato, tal autorização ainda não consta de nossa legislação, mas há diversos casos práticos em que juízes vêm autorizando. Vejamos a seguinte ementa, que trata de hipótese de aborto eugênico:

\footnotetext{
HC no 459242020128260000 SP 0045924-20.2012.8.26.0000 TJ-SP: Habeas Corpus Preventivo. Pedido de interrupção de gravidez. O feto padece de "Trissomia do Cromossomo 18" ou "Síndrome de Edwards". Relatório de Acompanhamento Genético aponta para inviabilidade de sobrevida ao feto, classificando o caso como emergência obstétrica grave diante do risco à vida da gestante. Presente a hipótese legal de aborto terapêutico ou profilático. Ordem concedida, referendada a liminar. HC: 459242020128260000 TJ - SP.
}

No caso acima, não há só a questão do aborto eugênico, mas também do necessário, uma vez que há risco de morte da gestante. Nota-se que há jurisprudência sendo formada no país nesse sentido. 
Id on Line Revista Multidisciplinar e de Psicoloqia

Id on Line Multidisciplinary Journal and Psycology

Esta prática é ainda proibida no País, mas a questão dos anencéfalos foi levada mais adiante, como veremos mais à frente no capítulo 5.

\section{Aborto Econômico-Social}

Este é caracterizado pela prática do aborto com alegações de que a gestante não possui condições econômicas para manter uma condição mínima de existência àquela criança. Não é autorizado no ordenamento jurídico brasileiro.

\section{Posicionamentos Religiosos}

É quase impossível falar da questão do aborto, seja ele de anencéfalo ou não, sem lembrar da questão religiosa. Se basicamente, é ela que motiva as reações nas pessoas em relação a esta questão e que faz causar tanta repercussão. É lógico que a religião, de forma geral, não comanda as decisões do Direito a esse respeito, mas acaba influenciando, já que quem faz o Direito são as pessoas, e cada uma possui um embasamento filosófico-religioso pessoal que acaba por interferir.

Porém traremos aqui, de forma breve, o posicionamento de algumas religiões, mas de forma neutra, tendo em vista que esse não é o foco da problemática abordada.

\section{Catolicismo}

A igreja católica sempre se posicionou contrariamente à prática do aborto em qualquer situação, mesmo naqueles enquadrados no art. 128. Condena os procedimentos que atentem contra a vida do feto, porém, não condena a morte do feto que venha a ocorrer de forma indireta para salvaguardar a vida da mãe.

O catecismo atual da Igreja Católica em seu cânone 2.270, afirma que "A vida humana deve ser respeitada e protegida de maneira absoluta a partir do momento da concepção. Desde o primeiro momento da sua existência, o ser humano deve ver reconhecidos os seus direitos de pessoa, entre os quais o direito inviolável de todo ser inocente à vida.”. . Diz ainda o catecismo: 
Id on Line Revista Multidisciplinar e de Psicoloqia

Id on Line Multidisciplinary Journal and Psycology

Cânone 2.272: O direito inviolável de todo indivíduo humano inocente à vida constitui um elemento constitutivo da sociedade civil e da sua legislação $\left(n^{\circ} 2.272\right)$ (...) Visto que deve ser tratado como pessoa desde a concepção, o embrião deverá ser defendido em sua integridade, cuidado e curado, na medida do possível, como qualquer ser humano." ( $\mathrm{n}^{\mathrm{o}} 2.273$ ). (MOSCHETTO, 2009, p.21)

Quem pratica o aborto acaba sofrendo a excomunhão, bem como aquele que colabora. Já a pessoa que facilita, como os legisladores, não deve receber a Eucaristia.

\section{Protestantismo}

As igrejas protestantes são mais flexíveis em relação ao catolicismo, pois admitirem o aborto terapêutico, dando sempre grande valoração à vida da mãe, mas nunca como forma de controle de natalidade

\section{Judaísmo}

Para o judaísmo, é permitido o aborto em caso de risco para a saúde da mãe, pois considera o feto que oferece risco à sua genitora como um "rodef" (agressor), aqui não há de se comparar a atitude à crime de homicídio.

Para eles, o feto só se transforma em ser humano quando nasce, e se torna pessoa após um mês do seu nascimento.

\section{Islamismo}

Para os islamitas, o nascituro só recebe a alma no $4^{\circ}$ mês de gestação. Enquanto não possui alma, enquanto não está revestido em carne e osso, não é humano, portanto, pode ser abortado. Se o aborto ocorrer antes de o feto se tornar "humano", então a indenização a ser paga é leve. Mas se ocorrer após o feto se tornar um ser animado, o aborto é punido com o assassinato do que o causou.

O Corão condena qualquer ato de matar, mas em caso de risco à vida da mãe, ela é a detentora da vida principal, e deve ser mantida. 


\section{Espiritismo}

Para o espiritismo, concordam, de maneira geral, que aborto é um crime. O feto desenvolve um laço fluídico com seu corpo, que se solidifica com seu nascimento e só se rompendo com a morte. Os seguidores de Allan Kardec acreditam que aqueles que privarem o feto de seu nascimento sem uma motivação justa, terão naquela alma um inimigo para aquela ou futuras encarnações.

Em caso de risco para a vida da mãe, é preferível, assim como nas demais doutrinas, que seja mantida a vida da mãe. Já em relação ao aborto, desaprovam, considerando que a alma do feto que está sendo gerado não deu causa àquele episódio, sendo que o trauma existirá independentemente do nascimento ou não daquela criança.

Para eles, o direito à vida está acima de um “ilusório" conforto psicológico da mulher.

\section{Budismo}

No site Budismo Primordial HBS, tem-se uma nota a respeito da questão do aborto: Somos contra. Também somos contra condenar de modo religioso quem cometeu. O budismo prega a consciência. Devemos rezar para que as pessoas tenham consciência da importância da vida e que sejam responsáveis pelos seus atos. Oramos por todos os falecidos abortados e suas respectivas mães, que não encontram orientação adequada para superarem a dificuldade de conviver com este peso.

Em linhas gerais, o budismo é contra o aborto, mesmo porque uma de suas diretrizes é a rejeição à violência, e tirar a vida do feto poderia ser uma forma de violência.

Como se pode observar, neste tópico, volta e meia falou-se no direito de vida do nascituro, mas também da preservação da vida da gestante. E isso será o foco da discussão do próximo tópico.

\section{Anencefalia}

Em um conceito médico, a anencefalia é considerada por Gisleno Feitosa, como: 
Consiste na ausência parcial ou completa da abobada craniana, bem como da ausência dos tecidos superiores com diversos graus de má formação e destruição dos rudimentos cerebrais. Em suma, anencefalia significa 'sem encéfalo', sendo encéfalo o conjunto de órgãos do sistema nervoso central, contidos na caixa craniana”. (2006, p. 18)

José Aristodemo Pinotti, por seu turno, informa que: “A anencefalia é resultado da falha de fechamento do tubo neural, decorrente da interação entre fatores genéticos e ambientais, durante o primeiro mês de embriogênese" (PINOTTI, 2004).

A definição majoritária por estudiosos sobre a anencefalia a diz como uma má formação fetal, mais frequente e mais grave a se constituir em anomalia congênita, caracterizada pela ausência total ou parcial do encéfalo e da calota craniana, proveniente de defeito de fechamento do tubo neural durante a formação embrionária, entre os dias 23 e 28 da gestação.

Há, porém, divergência quanto ao dia que ocorre a má formação congênita, que culmina com a anencefalia. Alguns doutrinadores acenam que seria entre os dias $21^{\circ}$ e $26^{\circ}$ da gestação; e outros que seria entre o $16^{\circ}$ e $26^{\circ}$. A área cérebro-vascular é coberta por um saco epitelial. Em $46 \%$ dos casos, não existem hemisférios cerebrais, havendo apenas rudimentos nos outros 54\%. O cerebelo é ausente em $85 \%$ e o tronco cerebral ausente em $75 \%$.

Pela etimologia da palavra, pode-se dizer que a anencefalia caracterizada pela ausência, completa ou parcial, dos tecidos encefálicos (cérebro com seus hemisférios e o cerebelo), comumente associada à deficiência de certos nutrientes, mormente ácido fólico. Também é válido esclarecer que em decorrência do não-fechamento do tubo neural, o anencéfalo, não desenvolve o couro cabeludo, a calota craniana (ossos frontal, occipital e parietal) e as meninges.

Seguindo a descrições de PIERANGELI, onde o feto anencéfalo possui a aparência de uma rã, na medida em que é totalmente falto da calota craniana e da cobertura das demais estruturas neurológicas (PIERANGELI, 2008, p. 40). E devido a essa ausência de completude das estruturas corpóreas a patologia é facilmente identificada e isso é possível ainda no início da gestação.

Com base nas definições acima podemos constatar que os anencéfalos possuem características físicas bem próprias que refletem exatamente a ausência dos tecidos cerebrais. Desse modo que, os portadores dessa doença possuem os olhos saltados das órbitas e o crânio achatado, devido à ausência de alguns ossos, com a exposição da parte do cérebro que se desenvolveu ou do deformado tronco neural, tendo sua aparência assemelhada a anfíbios. 
A Lei $9.434 / 1997$ no artigo $3^{\circ}$ traz em seu bojo:

\begin{abstract}
A retirada post mortem de tecidos, órgãos ou partes do corpo humano destinados a transplante ou tratamento deverá ser precedida de diagnóstico de morte encefálica, constatada e registrada por dois médicos não participantes das equipes de remoção e transplante, mediante a utilização de critérios clínicos e tecnológicos definidos por resolução do Conselho Federal de Medicina.
\end{abstract}

Sendo isto reafirmado na Resolução 1480/97 do Conselho Federal de Medicina, onde também vem a consideram que, "a parada total e irreversível das funções encefálicas equivale à morte, conforme critérios já bem estabelecidos pela comunidade científica mundial". Ao ser estabelecido como requisito essencial para a retirada de órgãos necessários a comprovação da morte encefálica da pessoa como fato que determina a sua morte, no caso do anencéfalo, o argumento mais utilizado é de que ele, por não ter desenvolvido seu sistema nervoso e, consequentemente, não possui cérebro. Desta forma, seria este considerado sem vida.

O Conselho Federal de Medicina também traz a Resolução de $n^{\circ} 1.752 / 04$ onde trata da chamada "autorização ética do uso de órgãos e/ou tecidos anencéfalos para transplante, mediante autorização dos pais.". Temos, também, a recente Resolução deste mesmo órgão, de $\mathrm{n}^{\circ} 1.989 / 2012$, em que trata sobre o procedimento para diagnóstico de anencefalia, visando à antecipação terapêutica do parto.

\title{
Princípio da Dignidade da Pessoa Humana
}

A nossa Carta Magna traz no inciso III de seu artigo $1^{\circ}$ a proteção à dignidade da pessoa humana. Este é considerado o princípio norteador de todos os direitos inerentes ao ser humano, com fundamental importância em nosso país. É um princípio que possui uma linha impositiva para o Estado, pois o mesmo assumiu a partir da promulgação da Constituição de 1988 a responsabilidade de através de políticas públicas garantir a realização de direitos básicos à população.

Rizzato Nunes afirma que:

É ela, a dignidade, o primeiro fundamento de todo o sistema constitucional posto e o último arcabouço da guarda dos direitos individuais. A isonomia serve, é verdade, para o equilíbrio real, porém visando concretizar direito à dignidade. É a dignidade que dá a direção, o comando a ser considerado primeiramente pelo intérprete. 
Coloque-se, então, desde já que, após a soberania, aparece no Texto Constitucional à dignidade como fundamento da República brasileira." (2003; pg. 45).

Pode-se perceber que a intenção do legislador constituinte é o de garantir o máximo respeito à essência humana, compreendendo nessa visão toda a sua complexidade, ou seja, englobando a integridade física e psíquica, a saúde, a honra, a qualidade de vida, dentre outros. Diante disto, é fácil perceber que impedir uma gestante de interromper uma gestação de feto anencéfalo configura-se uma ofensa ao princípio da dignidade da pessoa humana.

\footnotetext{
Dignidade da pessoa humana é um valor supremo que atrai o conteúdo de todos os direitos fundamentais do homem, desde o direito à vida. (...) daí decorre que a ordem econômica há de ter por fim assegurar a todos a existência digna (art. 170), a ordem social visará à realização da justiça social (art. 193), a educação, o desenvolvimento da pessoa e seu preparo para o exercício da cidadania (art. 205) etc, ao como meros enunciados formais, mas como indicadores do conteúdo eficaz da dignidade da pessoa humana”. (SILVA, 2001, p. 109).
}

Esse conceito mais amplo de dignidade da pessoa humana faz-se perceber que no caso dos anencéfalos, há um conflito entre os direitos do nascituro e da mãe, devendo haver um equilíbrio de valores para o alcance da melhor solução possível. Com base nisso a OAB (Ordem dos Advogados do Brasil) também não deixou de posicionar-se, como será visto no tópico a seguir.

\section{Interrupção de gestação de anencefálico não é aborto: posicionamento da OAB}

O Conselho Federal da Ordem dos Advogados do Brasil decidiu, por maioria de votos, considerar que a interrupção da gravidez de feto anencefálico não é considerada prática abortiva. A matéria foi examinada pelos 81 advogados que compõem o Conselho, na sede da OAB, após a decisão do ministro do Supremo Tribunal Federal, Marco Aurélio, que concedeu liminar à Confederação nacional dos Trabalhadores na Saúde (CNTS) para reconhecer o direito constitucional de gestantes que decidam realizar operação de parto de fetos anencefálicos.

$\mathrm{Na} \mathrm{OAB}$, a decisão da maioria dos conselheiros foi tomada com base no voto do relator da matéria na entidade, o conselheiro federal pela Bahia, Arx Tourinho. Segundo ele, só pode existir aborto se houver possibilidade de vida do feto. A seguir destaca-se algumas partes do voto quem vem ratificar tal posicionamento: 
Nosso Código Penal não conceituou aborto. Menciona-o, tipificando condutas, porém, sem afirmar o que, efetivamente, seja. Isso foi deixado para a doutrina e a jurisprudência. E, por esse ângulo, constata-se que só pode haver aborto, se há possibilidade de vida e de sobrevida. Não é aceitável que se saiba, previamente, que o feto não possui qualquer condição de sobrevida e, ainda assim, se tenha como aborto a interrupção da gravidez, que pressupõe a existência de outro ser que tenha possibilidade de vida própria. O feto anencefálico é uma patologia. [...] A Justiça não pode olvidar essa realidade. Não se trata de interrupção de gravidez em razão de eugenia, seletividade ou de sentimentalismo, mas, sim, de circunstância indiscutível de que o feto não terá sobrevida, porque o feto é sub-humano ou inumano. Não se deve olvidar das palavras de Giovanni Berlinguer "O aborto é o desfecho trágico de um conflito em que estão envolvidos de um lado um ser em formação, do outro as aspirações e necessidades de uma mulher" (Bioética cotidiana, Editora UNB, tradução de Lavínia Porciúncula, 2004, p. 47). Ora, se não há, em realidade, ser em formação, de um lado, e aspirações e necessidades de uma mulher, de outro lado, não há desfecho trágico, não há, portanto, aborto. Expele-se um ser malformado. Expele-se uma patologia. [...] Com efeito, o artigo 196, da Carta Magna, reza:"A saúde é direito de todos e dever do Estado, garantido mediante políticas sociais e econômicas que visem à redução do risco de doença de outros agravos e ao acesso universal e igualitário às ações e serviços para sua promoção, proteção e recuperação".Se a mulher, em gestação de um feto anencefálico, pode correr risco de vida, porque, segundo a literatura médica, cerca de cinqüenta por cento desses fetos têm morte intra-uterina, evidente que o direito à saúde da mulher deve prevalecer. Não só. Registram hospitais e clínicas médicas o profundo transtorno psicológico de que padece a mulher, quando aguarda o parto de um ser sub-humano, sem cérebro, com forma de gente, mas, sem a essência do humano.É evidente que a gestante, nessas circunstâncias, tem o direito de velar por sua saúde. [...] Em conclusão, propomos que esta Col. Casa do advogado, mas, também, da liberdade e do respeito à dignidade da pessoa humana, se manifeste pelo direito de a gestante interromper, sempre que assim desejar, uma gravidez, onde em gestação se ache um feto anencefálico, porque o Direito não é, nem pode, ser estático, não é, nem pode, ser contemplativo de uma realidade que passou, ignorando os avanços da ciência.

A seguir também veremos como se deu o ponto de vista jurídico através do Julgamento da ADPF 54.

\section{A argüição de descumprimento de Preceito Fundamental $n^{\circ} .54$}

A Confederação Nacional dos Trabalhadores na Saúde (CNTS), entidade nacional representativa de profissionais ligados à área da saúde, com objetivo de discutir a possibilidade de antecipação de parto em casos de anencefalia, os chamados partos terapêuticos, propôs a ADPF n. 54 em 17 de junho de 2004. Apresentando como fundamento jurídico a violação de preceitos fundamentais relacionados aos princípios da legalidade, dignidade da pessoa humana, autonomia da vontade e outros relacionados à saúde. Buscando a manifestação da Suprema Corte que possibilitasse a interpretação dos dispositivos do Código Penal que possibilitassem a prática do dito aborto sem o entendimento de que isto resulta em violação do direito à vida. 
Id on Line Revista Multidisciplinar e de Psicoloqia

Id on Line Multidisciplinary Journal and Psycology

Uma liminar foi concedida em 02 de agosto de 2004 neste caso, em que foi determinada a suspensão dos processos ainda não tramitados em julgado que tratavam deste mesmo tema, assim como reconheceu o direito às gestantes de se submeterem ao procedimento de aborto quando fosse constatada a anencefalia.

Porém só no ano de 2012, o Plenário do STF, por maioria de votos e nos termos do voto do Relator, julgou procedente a ação para declarar a inconstitucionalidade da interpretação mediante a qual a interrupção da gravidez de feto anencéfalo é conduta tipificada nos artigos 124, 126 e incisos I e II do artigo 128, todos do Código Penal, contra os votos dos senhores Ministros Ricardo Lewandowski e Cezar Peluso (Presidente), que a julgaram improcedente. Abaixo a transcrição da redação do entendimento de cada Ministro que votou pela procedência:

- Min. Marco Aurélio (relator): "O feto anencéfalo é incompatível com a vida. É desproporcional proteger o feto que não sobreviverá em detrimento da saúde mental da mulher", "O aborto é um crime contra a vida. O Estado tutela uma vida em potencial. No caso do anencéfalo não existe vida possível”;

- Min. Rosa Weber: "Não há interesse em se tutelar uma vida que não vai se desenvolver socialmente. Proteger a mulher nesse caso é proteger a sua liberdade de escolha.";

- Min. Luiz Fux: "Ao redigir os artigos do Código penal sobre aborto, o legislador não sabia que seria possível, no futuro, identificar a anencefalia ainda na gestação. É uma questão de saúde pública”, "Impedir a interrupção da gravidez nesses casos implica em tortura, o que é vedado pela Constituição";

- Min. Cármen Lúcia: "O feto anencéfalo não tem viabilidade de desenvolver uma vida extra-uterina. A anencefalia é um trauma para todos, não só para a gestante”;

- Min. Carlos Ayres Brito: "Se o homem engravidasse o aborto já seria lícito há muito tempo", "sob o início da vida, a Constituição é de um silêncio de morte", "O grau de civilização de uma sociedade se mede pelo grau de liberdade de uma mulher", "Levar as últimas consequências esse martírio contra a vontade da mulher, corresponde a tortura. Ninguém pode exigir de outro que se assuma como mártir, o martírio é voluntário, quem quiser assumir que o faça, ninguém está proibindo";

- Min. Gilmar Mendes: "O aborto neste caso zela pela saúde psíquica da mulher. O legislador de 1940 não sabia das ferramentas do futuro para identificar a anencefalia na gestação.";

- Min. Celso de Mello: "O único critério a ser utilizado na solução da controvérsia agora em questão é o que se fundamenta no texto da Constituição, nos tratados internacionais e nas leis da República", "não é aborto como estabelecida em lei. O feto anencéfalo não está vivo e sua morte não decorre de práticas abortivas".

Deve-se deixar claro que isto não implica em nenhuma obrigação à gestante. Pelo contrário, constitui uma faculdade, uma liberdade de escolha. 


\section{Considerações Finais}

Ante o exposto, pode-se constatar que o bem maior a ser tutelado pelo direito é a vida, podendo-se até afirmar que foi em razão desta que as regras que regem a sociedade, de forma positivada ou não, foram criadas. O ser humano tem a necessidade de estar sempre seguindo regras para poder ter uma existência digna e quando nossa Constituição garante a tutela desse bem maior, ela também puxa para si a responsabilidade e obrigação de apresentar uma solução plausível, que venha a equilibrar as relações caso as regras impostas por ela se confrontem.

As questões do aborto e da eutanásia são questões de grande repercussão na sociedade uma vez envolve posicionamentos de diversas áreas como do nosso ordenamento jurídico, da Ordem dos Advogados do Brasil, de organizações religiosas, do estudante acadêmico de Direito, dentre outros.

A Constituição Federal não só nos garante como bem jurídicos necessários para uma vivência digna, o funcionamento biológico do indivíduo, que seria um mero existir, como também o seu bem estar físico, mental e espiritual, resguardando o direito a intimidade, privacidade, consciência, crença, segurança, educação, cidadania, lazer, saúde e outros.

Como visto antes, a anencefalia, ausência da completude do sistema nervoso do feto, já é suficiente para a inviabilidade da sobrevivência da criança, que mesmo resistindo ao parto sobrevive poucos instantes e, em casos muito raros, dias. E não podendo deixar de ressaltar que ainda não existe na ciência qualquer forma de reversão do quadro.

"A maioria dos anencéfalos sobrevivem no máximo 48 horas após o nascimento. Quando a etiologia for brida amniótica podem sobreviver um pouco mais, mas sempre é questão de dias. As gestações de anencéfalos causam, com maior frequiência, patologias maternas como hipertensão e hidrâmnio (excesso de líquido amniótico), levando as mães a percorrerem uma gravidez com risco elevado" (PINOTTI, 2004).

Embora a Constituição proteja a vida de forma geral, inclusive a uterina, não podemos deixar de levar em conta o bem estar e a segurança à saúde da gestante, quem no caso concreto é a vida efetiva em questão, já que a vida do feto é inviável. E considerando a Lei de Transplante 
Id on Line Revista Multidisciplinar e de Psicoloqia

Id on Line Multidisciplinary Journal and Psycology

de Órgãos, que afirma, que há a morte com o encerramento da atividade cerebral, sequer poderíamos falar que o anencéfalo possuiu vida.

Observe o quanto é desproporcional a imposição a uma mulher de manter uma gestação por vários meses de um natimorto, causando-lhe a dor e angústia de tanto ter sua vida em risco, como ter dentro de si algo que não prosperará. Vindo, assim, de forma agressiva à ameaçar sua integridade física, moral e mental. A manutenção da gestação só virá a causar o sofrimento da mãe, e numa análise mais minuciosa percebe-se que há uma ofensa também a garantia do inciso III, do artigo $5^{\circ}$ da $\mathrm{CF}$, onde nos traz a garantia que "ninguém será submetido a tortura, nem a tratamento desumano ou degradante.”. Implicando em grandes ataques a sua dignidade.

A interpretação do princípio da dignidade da pessoa humana já é suficiente para respaldar a defesa da antecipação terapêutica do parto de feto anencéfalo, uma vez que, não há hierarquia entre princípios e seus conflitos devem ser resolvidos de forma a equilibrar os valores, sendo nesses casos a liberdade da gestante de escolher, ou não, a interrupção da gravidez, a maneira mais ponderada e menos traumática de resultados inevitáveis. Dando-lhe o direito de autopreservar-se.

Sobre a negativa do direito de eutanásia àqueles pacientes em estado terminal, onde não lhe resta mais quase nenhuma dignidade a não ser o direito "nu e cru" de existir, pois não lhe há mais preceitos fundamentais estatuídos pela nossa Carta Magna como dignos e sendo de sua vontade ou de seus responsáveis, quando o primeiro não puder expressar-se, configura-se mais uma vez em ofensa ao inciso III, artigo $5^{\circ}$ da mesma. Uma vez que não há nada mais indigno do que a obrigação de existir à força em decorrência de um ordenamento jurídico engessado, num estado de sofrimento sem nenhuma opção de reversão.

Aqui não há de se falar em eutanásia para qualquer mera doença ou estado, mas sim dos imensos sofredores que encontram-se em estado de total vegetação, onde não possa exercer mais nenhum ato de cidadania a não ser a simples existência. As garantias fundamentais tem que promover o bem-estar das pessoas e viver não pode tornar-se um fardo, uma obrigação para os que não tem mais nenhuma perspectiva de reversão de seu quadro, sofrendo em razão de uma doença e resultando inevitavelmente a espera de uma morte totalmente traumática e nada digna. Onde vem a ser mitigado a idéia principal que coloca o indivíduo no plano de formar a si e a sua vida conforme sua capacidade de autodeterminação de sua conduta. 
É de fundamental importância que o jurista tenha uma mente democrática, uma vez que não existem verdades inabaláveis e teorias indestrutíveis, sendo essencial notar as mudanças que estão ocorrendo todos os dias na interpretação do direito, sabendo atualizar a sua opinião aos avanços históricos, culturais e científicos a realidade que se encontre. Ponderando os valores envolvidos e optando pelo direito que melhor assegure a dignidade da pessoa humana.

Enfim, em decorrência do direito à vida em acordo com o princípio da dignidade da pessoa humana, o aborto de feto sem expectativa de vida extra-uterina e eutanásia de enfermo em situação degradante ou desumana não seriam condutas antijurídicas por aqui não haver dano social, nem alguma intenção de ferir o interesse da sociedade. Pelo contrário seria a primeira vez que se falaria em morte e aborto como gesto de preservação e porque não de carinho ou ato de amor e compaixão.

\section{Referências}

ANALAFT NETO, Jorge. Anencefalia: opinião. Disponível em: <http://www.ambitojuridico.com.br/site/index.php?n_link=revista_artigos_leitura\&artigo_id=10385>. Acesso em 26 de maio de 2015;

BUlOS, Uadi Lammêgo. Curso de Direito Constitucional / Uadi Lammêgo Bulos. - São Paulo: Saraiva, 2007.

CARVALHO, Kildare Gonçalves. Direito Constitucional / Kildare Gonçalves Carvalho. - 43. ed., rev. atual. e ampl. - Belo Horizonte: Del Rey, 2008.

CHIMENTI, Ricardo Cunha. Curso de Direito Constitucional / Ricardo Cunha Chimenti... [et al.]. São Paulo : Saraiva, 2007.

CONSELHO FEDERAL DE MEDICINA. RESOLUÇÃO CFM nº 1949/2010. (Publicada no D.O.U., 6 julho de 2010, seção I, p.85). Disponível em <http://www.portalmedico.org.br/resolucoes/cfm/2010/1949_2010.htm>. Acessado em 27 de maio de 2015.

CONTEÚDO JURÍDICO. A garantia jurídica do princípio da dignidade da pessoa humana, como pressuposto do vigente estado democrático de direito, que parece ser apenas uma garantia teórica. Disponível em <http://www.conteudojuridico.com.br/artigo,a-garantia-juridica-do-principio-dadignidade-da-pessoa-humana-como-pressuposto-do-vigente-estado-democratico-,38374.html>.

Acessado em 04 de maio de 2015.

CONTEÚDO JURÍDICO. Aborto: aspectos polêmicos, anencefalia e descriminalização. Publicado em 30 de Maio de 2012. Disponível em < http://www.conteudojuridico.com.br/artigo,aborto-aspectospolemicos-anencefalia-e-descriminalizacao,37270.html>. Acessado em 06 de maio de 2015. 
Id on Line Revista Multidisciplinar e de Psicoloqia

Id on Line Multidisciplinary Journal and Psycology

CUNHA, Rogério Sanchez. Direito Penal: Parte Especial, 2ª Ed. São Paulo, RT, 2008.

DINIZ, Maria Helena. O Estado Atual do Biodireito, 6a Ed. São Paulo, Saraiva, 2009.

DOCUMENTOS JURÍDICOS PARECERES. Disponível em <http://www.ghente.org/doc_juridicos/parecerer_oab_anencefalo.htm>. Acessado em: 04 de maio de 2015.

E SILVA, Fernando Duarte Leopoldo. JurisWay. ASPECTOS MÉDICOS E JURÍDICOS DO ABORTO. Publicado em 18 de março de 2009. Disponível em <http://www.jurisway.org.br/v2/dhall.asp?id_dh=1201>. Acessado em 06 de maio de 2015.

FEITOSA, Gisleno. Interrupção da gestação em caso de anencefalia. In: COSTA, Sergio;

FONTES, Malu \& SQUINCA, Flávia. Tópicos em bioética. Brasília: Letras Livres, 2006.

FRANCISCONI, Carlos Fernando e GOLDIM, José Roberto. Tipos de Eutanásia. Disponpivel em <http://www.ufrgs.br/bioetica/eutantip.htm>. Acessado em 04 de maio de 2015.

HOLANDA, Aurélio Buarque de. Novo Dicionário Aurélio da Língua Portuguesa, 2.a edição revista e ampliada. Editora Nova Fronteira. São Paulo: 1994.

\section{JURISWAY. DIREITO À VIDA: CONSIDERAÇÕES ACERCA DO ABORTO E DA EUTANÁSIA. Publicado em em 26 de setembro de 2013. Disponível em <http://www.jurisway.org.br/v2/dhall.asp?id_dh=11914> Acessado em 04 de maio de 2015.}

JUSBRASIL. TJ-SP - HC: 459242020128260000 SP 0045924-20.2012.8.26.0000, Relator: Péricles Piza, Data de Julgamento: 23/04/2012, $1^{\text {a }}$ Câmara de Direito Criminal, Data de Publicação: 25/04/2012. Disponível em: http://tj-sp.jusbrasil.com.br/jurisprudencia/21674951/habeas-corpus-hc459242020128260000-sp-0045924-2020128260000-tjsp. Acessado em 24 de maio de 2015.

LEME, A. C. R. P. Tranfusão de sangue em testemunhas de Jeová. A colisão de direitos fundamentais. Jus Navigandi, Teresina, ano 9, n. 632, 1 abr. 2005. Disponível em: http://jus2.uol.com.br/doutrina/texto.asp?id=6545. Acesso em: 15 de maio de 2015.

MACEDO, T. F. A ponderação de interesses e o paciente Testemunha de Jeová. In: DireitoNet, Artigos. 05/06/2006. Disponível em: http://www.direitonet.com.br/artigos/x/26/64/2664/. Acesso em: 15 de maio de 2015.

MORAIS, Alexandre de. Direito Constitucional / Alexandre de Morais. - 23. ed. - 2. reimpr. - São Paulo: Atlas, 2007.

NOLASCO, Lincoln. Aborto: aspectos polêmicos, anencefalia e descriminalização. In: Âmbito Jurídico, Rio Grande, XV, n. 101, jun 2012. Disponível em: <http://ambitojuridico.com.br/site/index.php/?n_link=revista_artigos_leitura\&artigo_id=11874\&revista_caderno=3> . Acesso em maio 2015.

NUNES, Rizzato. O princípio constitucional da dignidade da pessoa humana. São Paulo: Saraiva, 2002. 
Id on Line Revista Multidisciplinar e de Psicoloqia

Id on Line Multidisciplinary Journal and Psycology

PIERANGELI, José Henrique. Anencefalia. Revista IOB de direito penal e processual penal. v. 8, n. 47, dez./jan. 2008.

PINOTTI, José Aristodemo. Anencefalia. Disponível em: http://www.ambitojuridico.com.br/site/index.php?n_link=revista_artigos_leitura\&artigo_id=10385. Acesso em 24 de maio de 2015.

REMOÇÃO E DOAÇÃO DE ÓRGÃOS. DEC. No 2.268/97 (Regulamento). LEI No 10.211/ 2001 ("post mortem"). Disponível em <http://www.soleis.adv.br/remocaodeorgaos.htm>. Acessado em 26 de maio de 2015.

SILVA E SOUZA, Jean Frederick e GOMES, Sheyla Polliana Macedo. Anencefalia: aborto ilegal ou inexigibilidade de conduta diversa?. Disponível em <www.esmarn.tjrn.jus.br/revistas> Acessado em 27 de maio de 2015.

SILVA, José Afonso da. Curso de Direito Constitucional Positivo / José Afonso da Silva. - 30a . ed. rev. e atual. - São Paulo: Malheiros, 2008.

SILVA, José Afonso da. Curso de Direito Constitucional Positivo, Malheiros, 18ª . Edição, p. 201

SILVA, José Afonso da. Curso de direito constitucional positivo. 19. ed. rev. e atual. São Paulo: Malheiros, 2001.

VOLGANE, Oliveira Carvalho. Biodireito. A anencefalia e o princípio da dignidade da pessoa humana no regime neoconstitucional brasileiro. Rio Grande. Disponível em < http://www.ambitojuridico.com.br/site/index.php?n_link=revista_artigos_leitura\&artigo_id=10385>. Acessado em $04 \mathrm{de}$ maio de 2015.

WEB ARTIGOS. O Crime de Aborto e Suas Principais Características. Publicado em 22 de março de 2009 em Disponpivel em <http://www.webartigos.com/artigos/o-crime-de-aborto-e-suas-principaiscaracteristicas/15847/>. Acessado em 05 de maio de 2015.

\section{Como citar este artigo (Formato ABNT):}

SOUZA, L.D.; FARIAS, A.A.; BEZERRA, P.E.; ROCHA, H.G. Direito à Vida: Aborto de Feto Anencéfalo e Eutanásia. Id on Line Revista Multidisciplinar e de Psicologia, Outubro de 2016, vol.10, n.31, p. 126-152. ISSN 1981-1179.

Recebido: 4/08/2016.

Aceito: 15/08/2016 